Research Article

\title{
Implementation of Optimal Protection Coordination for Microgrids with Distributed Generations Using Quaternary Protection Scheme
}

\author{
Panida Thararak $\mathbb{D}^{1,2}$ and Peerapol Jirapong $\mathbb{D}^{1}$ \\ ${ }^{1}$ Faculty of Engineering, Chiang Mai University, Chiang Mai 50200, Thailand \\ ${ }^{2}$ The Graduate School, Chiang Mai University, Chiang Mai 50200, Thailand \\ Correspondence should be addressed to Peerapol Jirapong; levinson331@gmail.com
}

Received 25 October 2019; Accepted 2 January 2020; Published 13 February 2020

Academic Editor: Changhwan Shin

Copyright (c) 2020 Panida Thararak and Peerapol Jirapong. This is an open access article distributed under the Creative Commons Attribution License, which permits unrestricted use, distribution, and reproduction in any medium, provided the original work is properly cited.

\begin{abstract}
The flexible operation of microgrids, along with the availability of distributed generation (DG) units, causes a variety of changes in short-circuit current levels, magnitudes, and directions, which has undesirable effects on the operation of protection systems. Conventional protection schemes use typical directional overcurrent relays (DOCRs) with limited operating capability, unable to respond to microgrid operations in the manner of short-circuit current changes. In this paper, a quaternary protection scheme implemented with dual-directional overcurrent relays (dual-DOCR) and a protection control strategy is developed for protecting against faults in microgrids, taking into account the existence of DGs and connection and disconnection of DG units. The optimal dual-DOCRs setting and coordination are formulated as an optimization problem solved by evolutionary programming to minimize the relay operating times. The proposed protection scheme is implemented with a centralized protection control system based on the smart grid concept to increase the adaptability of the dual-DOCRs, which have multiple relay setting groups in accordance with system state changes. The simulation case studies are performed using the IEEE 14-bus test system, which is modified as a meshed microgrid operation. Test scenarios, including possible operations of microgrids, DGs availabilities, and different fault events, are analyzed and discussed. The comparative studies and simulation results show that the proposed scheme provides efficient coordination between the primary and backup relays and increases the responsibility of the protection system, which can be observed from the significant reduction in the relay operating times, resulting in the enhancement of selectivity, sensitivity, and speed of microgrid protection systems.
\end{abstract}

\section{Introduction}

A microgrid is a form of active small-scale distribution system operated in a modern smart grid structure, which has gained more importance, especially in the manner of flexible operation in grid-connected and islanded modes to enhance reliability and security of electricity grids. The integration of distributed generators (DGs) to the microgrid is an essential part of supplying electricity to the loads when operating in the islanded mode. Distributed generations provide higher system efficiency and power quality with fewer environmental impacts than those of the traditional centralized power generation system.
The transitioning from traditional distribution systems to microgrids causes changes in the power flow and shortcircuit currents that can adversely affect the operation of the protection system [1]. The electrical power will change from one direction flow to bidirectional one. Meanwhile, shortcircuit current magnitude and direction will also change accordingly depending on the operating status of the microgrid, including the type, size, and location of the DGs installed in the system. The conventional protection system designed based on high short-circuit current in a radial system structure under a specific system state uses overcurrent relay equipped with nondirectional elements unable to respond to the dynamic system state changes and will fail 
to operate. Failure of the protection system causes various protection issues, including miscoordination, fault tripping, and blinding of protection, which results in the benefits from the microgrid with the integration of DG, which are significantly reduced [2]. The design and implementation of appropriate protection systems for the microgrid with DGs are, therefore, essential for increasing system reliability, security, efficiency, and resiliency.

The development of effective protection systems for the microgrid with DGs is important in determining the two main points: protective devices and protection schemes. The use of nondirectional overcurrent relays that operate regardless of the fault current direction leads to false tripping decisions due to the microgrid operations and the backfeed fault current from DGs [2]. Electromechanical and digital overcurrent relays equipped with directional components and a single relay setting have been developed to overcome the deficiency of faulty current detection [3]. Dual setting directional overcurrent relays (DOCRs) have been proposed in $[4,5]$ to improve the capabilities of conventional DOCRs for protecting meshed distribution systems with DGs. The proposed relays are equipped with two inverse time-current characteristics whose relay settings will depend on the forward and reverse fault directions. This feature contributes to improving performance in reducing relay operating times. However, the improvement of these relays to provide additional functionality for protecting against faults in microgrids is still a challenge in modern protection systems.

Protection schemes are a crucial part of the planning of the protective device operation according to the specified relay setting and coordination to ensure that the fault events are detected and cleared correctly as quickly as possible. Conservative protection schemes suggest automatically disconnecting the DG from the system in the event of any abnormalities due to safety and security concerns [6]. These methods limit the operation of electrical systems in the form of microgrids. Conventional protection schemes designed in accordance with the recommended practices provided by the IEEE and the IEC standards are used extensively by many electrical utilities to prevent faults in traditional distribution systems [7, 8]. The typical time-current characteristic for conventional overcurrent relays can be determined using the standard relay equations in $[8,9]$. Various protection schemes for distribution systems and microgrids that do not require communication capability have been presented in literature where several protection coordination methods have been proposed [10-12]. However, these methods do not take into account the availability of DGs and connection and disconnection of DGs, which cause the variation of fault currents. In addition, the optimal protection coordination using computational intelligence-based techniques such as particle swarm optimization (PSO) [13] and genetic algorithm (GA) [14] has been proposed for determining the optimal relay setting to minimize the total relay operating times. These protection schemes are determined according to specific system state and network configuration in which if any system changes occur, the relay settings must be reevaluated.
In recent years, the protection schemes designed for protecting against faults in microgrids with DGs have been developed in the literature, which can be categorized by the microgrid operations. The protection schemes for gridconnected mode only have been proposed in $[15,16]$. In [15], a protection scheme that relies on time-dependent characteristics of fault current is proposed to maximize DG connection. A protection scheme that uses conventional overcurrent relays with definite time grading has been presented in [16]. These methods are unclear about their implementation with the islanded microgrid. The protection scheme for islanded mode must be more sensitive because fault currents in islanding will be of much lower magnitudes than those of the grid-connected system. In this regard, protection schemes for particular islanded mode have been proposed in some literature. These methods are designed based on monitoring different system conditions, such as harmonic content of converter-based DGs (C-DGs) [17], output voltages of C-DGs [18], and symmetrical component combined with residual current [19].

The protection schemes developed for both grid-connected and islanded microgrids have been proposed in [20-22]. An implementation of undervoltage relay for islanded mode together with overcurrent relay for gridconnected mode, which does not require adaptive protection capability, is proposed in [20]. In [21], digital overcurrent relays that can update their setting based on microgrid functions are used for protecting microgrid with a radial system structure. A similar approach that uses an adaptive protection scheme along with communication using IEC 61850 is proposed in [22].

The previous works related to the development and implementation of protection schemes for microgrids with DGs have shown that these methods can be used sufficiently for the protection of faults occurring in grid-connected microgrids with uninterrupted DG connection in radial system structures. However, there is no mention in the literature for the optimal protection coordination of modern DOCRs that are used for microgrids in the mesh structures that take into account the connection and disconnection of the DG units. Therefore, an effective protection scheme, which can adjust the relay settings optimally according to the status of both the microgrid operations and the availability of the DGs, is still a challenge for engineers to improve the efficiency of the protection system.

In this paper, a novel quaternary protection scheme utilizing smart grid technologies and computational intelligence optimization has been developed for protecting microgrids taking into account the availability of DGs. The proposed protection scheme implemented with a centralized protection control strategy is capable of automatically adjusting the optimal relay setting and coordination in accordance with the operations of both microgrids and DGs. The intelligent electronic device- (IED-) based dual-directional overcurrent relay (dual-DOCR) with adaptive relay setting groups is implemented for protecting against shortcircuit faults considering both the forward and reverse fault current directions. The relay setting and coordination are optimally determined using the evolutionary programming 
(EP) technique to minimize the total relay operating times. The proposed approach aims to mitigate the protection problems arising from the operation of microgrids with the integration of DG units as well as enhance the selectivity, sensitivity, speed, and reliability of the protection system.

\section{Conventional Protection Scheme}

The conventional relay setting for DOCRs based on the IEC 60255 relay standard is to determine the two main parameters: relay setting current $\left(I_{\mathrm{s}}\right)$ and time multiplier setting (TMS) [23]. The operating time of the DOCR expressed in (1) is an inverse-time characteristic function of the relay setting values and the short-circuit current (I) passing through it.

$$
t=\frac{A \times \mathrm{TMS}}{\left(I / I_{\mathrm{s}}\right)^{B}-1},
$$

where $t$ is the operating time of protective relay. $I$ and $I_{\mathrm{s}}$ are the measured short-circuit current passing through the relay and the relay setting current, respectively. The parameters $A$ and $B$ are the constant values that change according to the time-current characteristics of DOCR.

The protection coordination for conventional DOCRs is a process of determining the operating sequence of the primary and backup relays in accordance with the relay settings and a specific fault current direction under the coordination time interval (CTI) criteria. A typical relay time-current characteristic curve showing the coordination between primary and backup relays is illustrated in Figure 1. Conventional protection schemes assign which relays will be either primary or backup in the system. Figure 2 shows an example of a three-bus meshed microgrid equipped with six DOCRs. If a fault occurs at the middle point of the line section between Bus 1 and Bus 2, relay $R 1$ will operate as the primary relay to protect the fault current flowing in the forward direction, and the next relay $R 5$, which has the same fault direction setting, will be its backup. Similarly, $R 2$ will operate as the primary relay and $R 4$ will be its backup, which is responsible for clearing the reverse fault current.

\section{Quaternary Protection Scheme}

In this paper, a new quaternary protection scheme equipped with intelligent electronic devices- (IEDs-) based dual-directional overcurrent relays (dual-DOCRs) is proposed for protecting against fault in meshed microgrids taking into account the operating status of both microgrids and DGs including the fault current directions. In addition, the proposed relay settings and coordination are optimized using an evolutionary programming (EP) approach. The centralized control strategy with monitoring and communication systems from smart grid technology is utilized for the implementation of the proposed scheme.

3.1. Quaternary Relay Setting and Coordination. The proposed dual-DOCR is capable of bidirectional fault current detection from the use of phase correlation between voltage

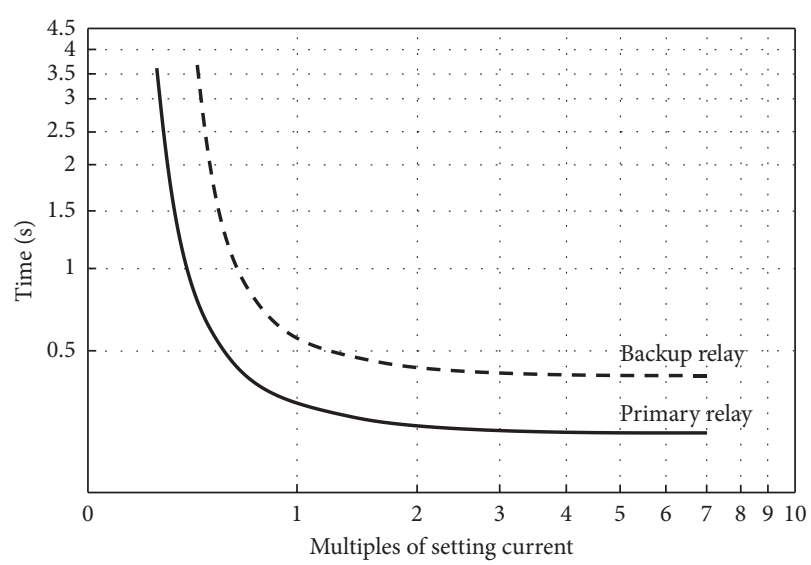

FIGURE 1: The conventional time-current curve and coordination of DOCRs.

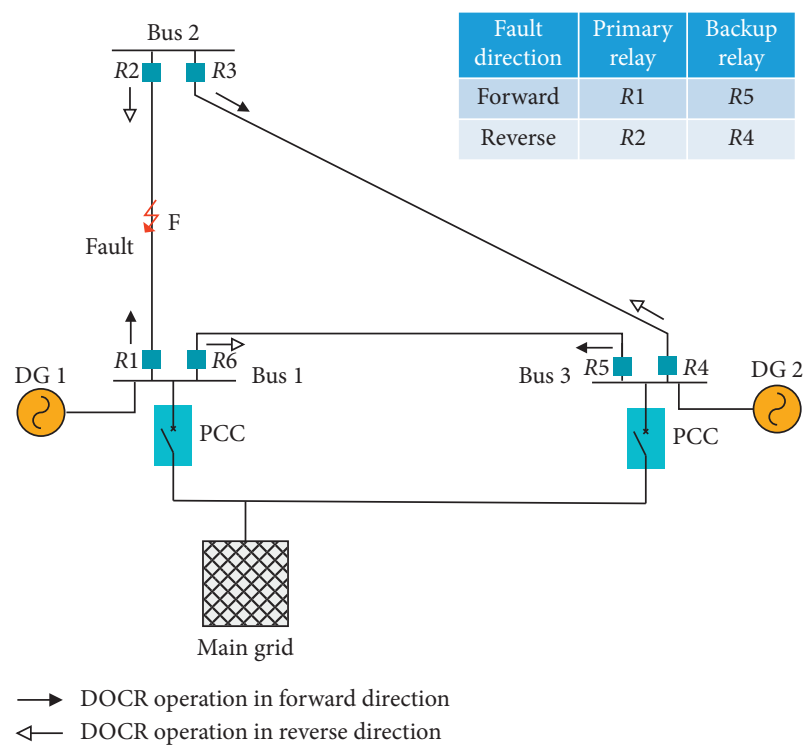

Figure 2: Operation of DOCRs with the conventional protection scheme.

and current with decision-making logic to discriminate the forward and reverse fault current directions. Each dualDOCR is equipped with a relay setting group consisting of four pairs of relay setting values according to the microgrid operations and fault current directions, as shown in Table 1. The quaternary inverse time-current curve of each dualDOCR is depicted in Figure 3. Regarding the dual-DOCR coordination, the relay that is closest to the fault location will operate as the primary relay. Then, the next relay that is closest to the primary relay, which has the same fault direction, is determined to be the backup relay. For the example depicted in Figure 4, if a fault occurs at point F, relay $R 1$ will operate as the primary relay for the fault current in the forward direction, and the next relay $R 6$ will be its backup. Similarly, relay $R 2$ will be the primary relay for the fault current in reverse direction, and the next relay $R 3$ is its backup. 
TABLE 1: A relay setting group for each system state.

\begin{tabular}{lcc}
\hline $\begin{array}{l}\text { Relay } \\
\text { setting } \\
\text { group }\end{array}$ & Microgrid state & $\begin{array}{c}\text { Fault current } \\
\text { direction }\end{array}$ \\
\hline$R_{\text {set }}^{1}$ & Grid-connected mode & Forward \\
$R_{\text {set }}^{2}$ & Grid-connected mode & Reverse \\
$R_{\text {set }}^{3}$ & Islanded mode & Reverse \\
$R_{\text {set }}^{4}$ & Islanded mode & Forward \\
\hline
\end{tabular}

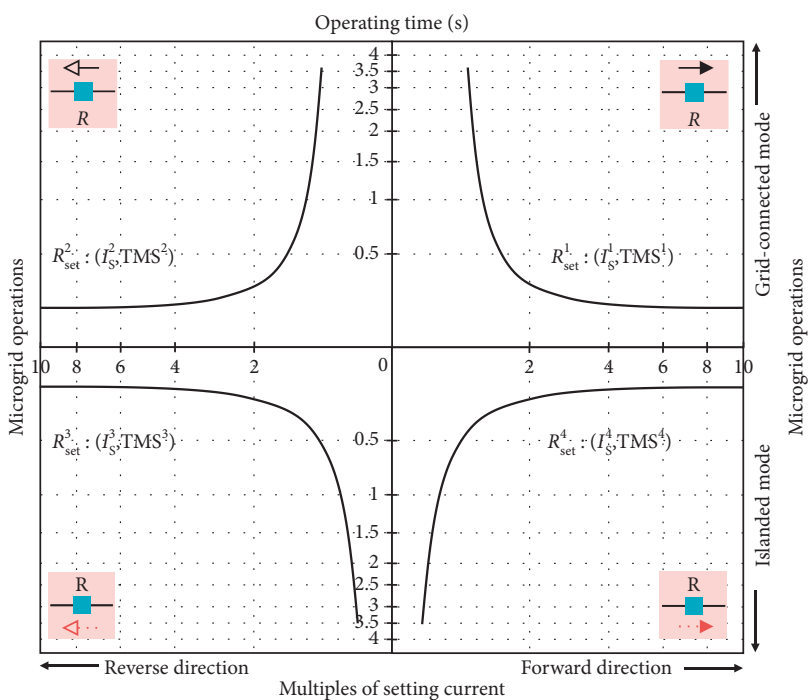

FIGURE 3: The proposed quaternary time-current curve for each dual-DOCR.

3.2. Optimal Protection Coordination. The dual-DOCR setting and coordination will be predefined into four relay settings for each system state. The relay operating time $(t)$ of each relay setting is determined from the inverse timecurrent characteristic function in (2).

$$
t_{i}^{n}=\frac{A \times \mathrm{TMS}_{i}^{n}}{\left(I_{i} / I_{s, i}^{n}\right)^{B}-1}
$$

where $i$ is the relay identifier and $n$ is the relay setting group identifier. The variables $t_{i}^{n}, \mathrm{TMS}_{i}^{n}$, and $I_{s, i}^{n}$ are the operating time, the time multiplier setting, and the current setting of the $i^{\text {th }}$ relay in the relay setting group $n$, respectively. $I_{i}$ is the fault current flowing through the $i^{\text {th }}$ relay. The constant relay characteristics $A$ and $B$ are set to be 0.14 and 0.02 , respectively.

The optimal dual-DOCR coordination is formulated as an optimization problem. The total relay operating times in (3) is defined as the objective function for the optimal relay setting and coordination to minimize the total relay tripping times in each relay setting group.

$$
\text { Minimize } t=\sum_{i=1}^{m}\left(t_{i}^{n}\right) \text {, }
$$

where $m$ is the total number of dual-DOCRs in the relay setting group $n$.

Regarding the coordination condition, the operating time of the primary relay and backup relay needs to be

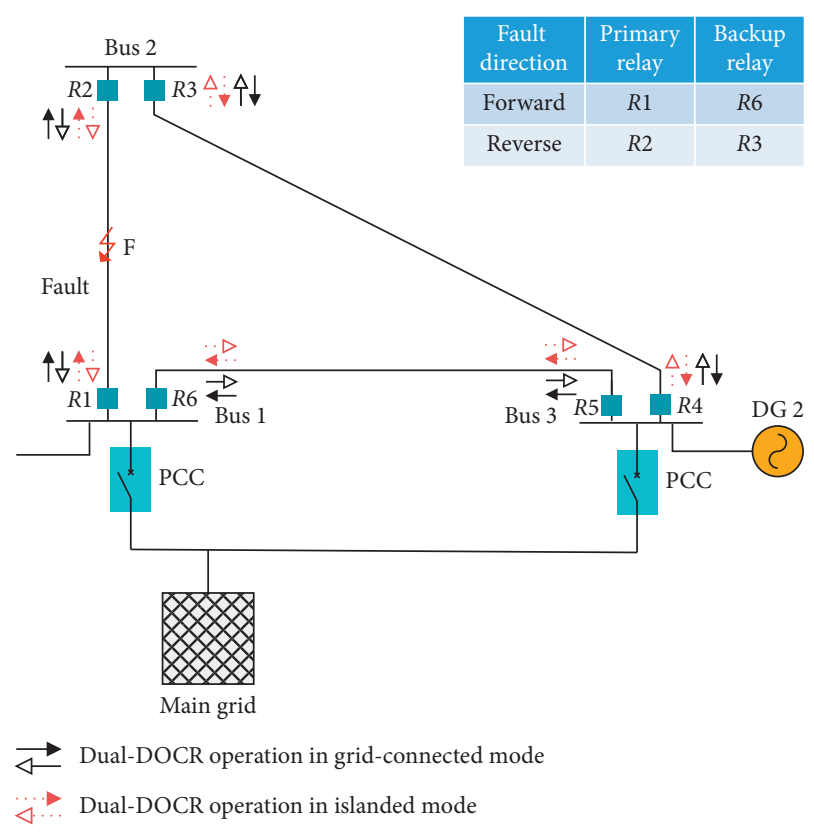

FIGURE 4: Operation of dual-DOCRs with the quaternary protection scheme.

controlled within the coordination time interval (CTI) constraint, which is a minimum time interval, $0.2-0.5 \mathrm{sec}$, allowed between the primary/backup relays operation. It is set to be $0.20 \mathrm{sec}$ for this study. Therefore, the coordination time constraint is defined in

$$
t_{i, \mathrm{bk}}^{n}-t_{i, \mathrm{pi}}^{n} \geq \mathrm{CTI}
$$

where $t_{i, \mathrm{pi}}^{n}$ and $t_{i, \mathrm{bk}}^{n}$ are the primary and backup relays operating times of the $i^{\text {th }}$ relay in the relay setting group $n$, respectively. In addition, the upper and lower relay setting limits can be defined in

$$
\begin{aligned}
I_{s, i, \min }^{n} & \leq I_{s, i}^{n} \leq I_{s, i, \max }^{n}, \\
\mathrm{TMS}_{i, \text { min }}^{n} & \leq \mathrm{TMS}_{i}^{n} \leq \mathrm{TMS}_{i, \text { max }}^{n},
\end{aligned}
$$

where $I_{s, i, \min }^{n}$ and $I_{s, i, \max }^{n}$ are the minimum and maximum limits of the current setting for the $i^{\text {th }}$ relay in each relay setting group $n$, which are determined from the load current calculation. $\mathrm{TMS}_{i, \min }^{n}$ and $\mathrm{TMS}_{i, \max }^{n}$ are the minimum and maximum boundaries of the time multiplier setting for the $i^{\text {th }}$ relay in each relay setting group $n$.

Evolutionary programming (EP) is an efficient optimization technique in which populations of individual solutions are evolved through mutation, random changes, competition, and selection. The EP approach in [24] is proposed to solve the optimal coordination problem. The optimization process shown in Figure 5 is performed using MATLAB and DIgSILENT PowerFactory software. The EP algorithm is created as an m-file script in MATLAB for evaluating the optimal solution. The load flow analysis and short-circuit calculation are carried out by a DPL script in DIgSILENT. The data exchange process and interactive communication between these analysis tools are automatically interchanged using the sw.csv file. 


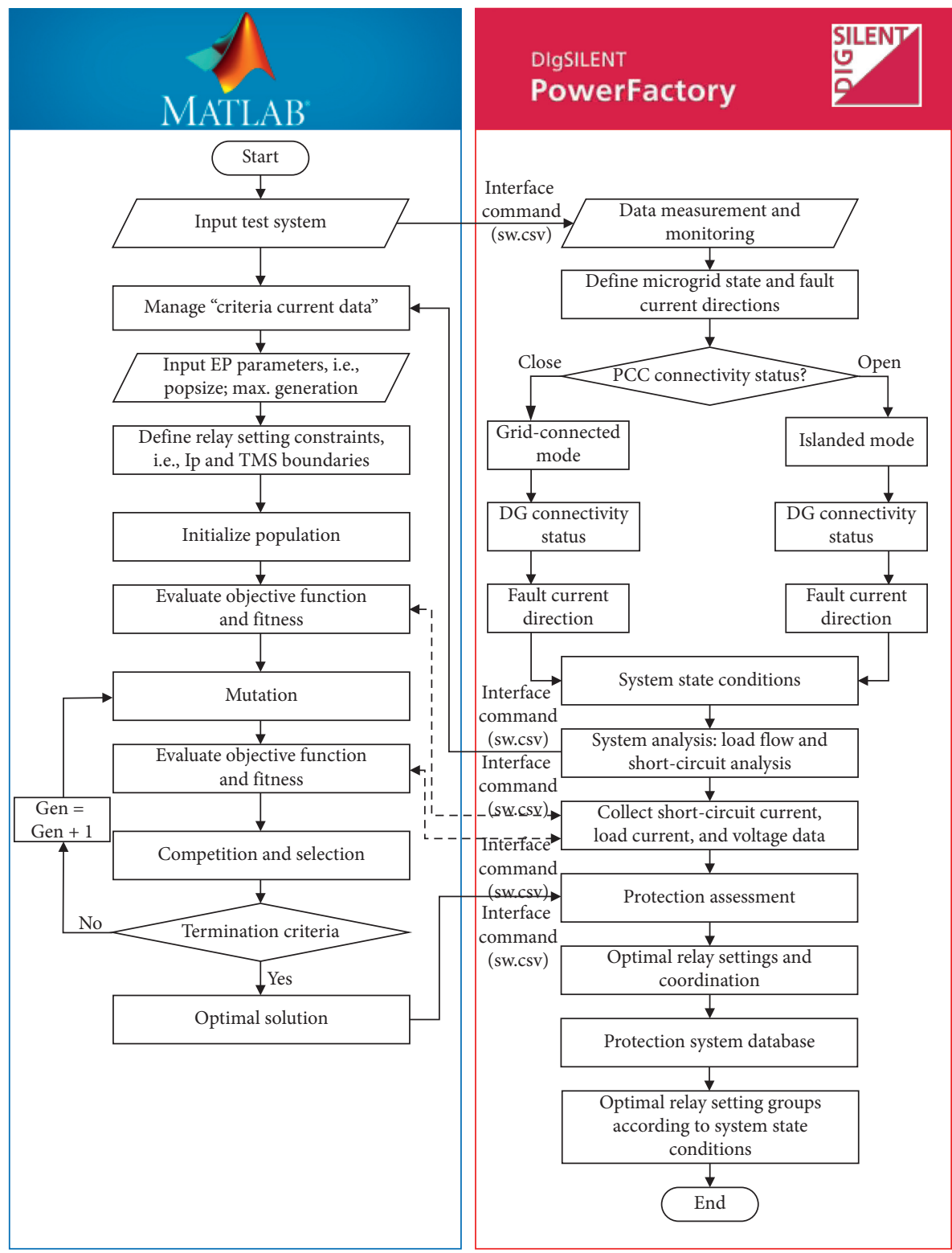

FIgURE 5: Flowchart of the optimal dual-DOCR setting and coordination.

3.3. Protection System Control Strategy. The implementation of the dual-DOCR configuration with the proposed protection system control strategy can be presented in Figures 6 and 7 . The protection control algorithm illustrated in Figure 7 consists of the system state monitoring of the microgrid operations and the availability of DGs, from which input data are the status of the point of common coupling (PCC) at the microgrid interconnection and the status of circuit breakers at the DGs. These data will be sent through the communication system conformed with the IEC 61850 standard [21] to the microgrid controller. The centralized protection control system (CPCS) is a function within the microgrid controller that is responsible for the operation and control of the protective relays. The CPCS will determine the present state of the system from the information received and compare it with the predefined system state and the matching of the optimal relay settings stored in the protection system database, as depicted in Figure 8. If the system state matches, CPCS will send the optimal relay setting group that is predefined for that state to each dualDOCR. On the contrary, if the system state does not match, CPCS will reassess the optimal relay settings in accordance with that new system state and update the protection system database.

The decision-making process for the operation of dualDOCR depends on the system state and the status of the fault current directions. The dual-DOCR will receive the operation setting corresponding to the present system state from the CPCS, which makes the relay ready to work regardless of the fault current directions. When the dual-DOCR detects a fault current, the relay will be able to distinguish the shortcircuit current direction from the phase correlation of voltage and current with the decision-making logic depicted in Figure 9. Any current flowing into the prespecified 


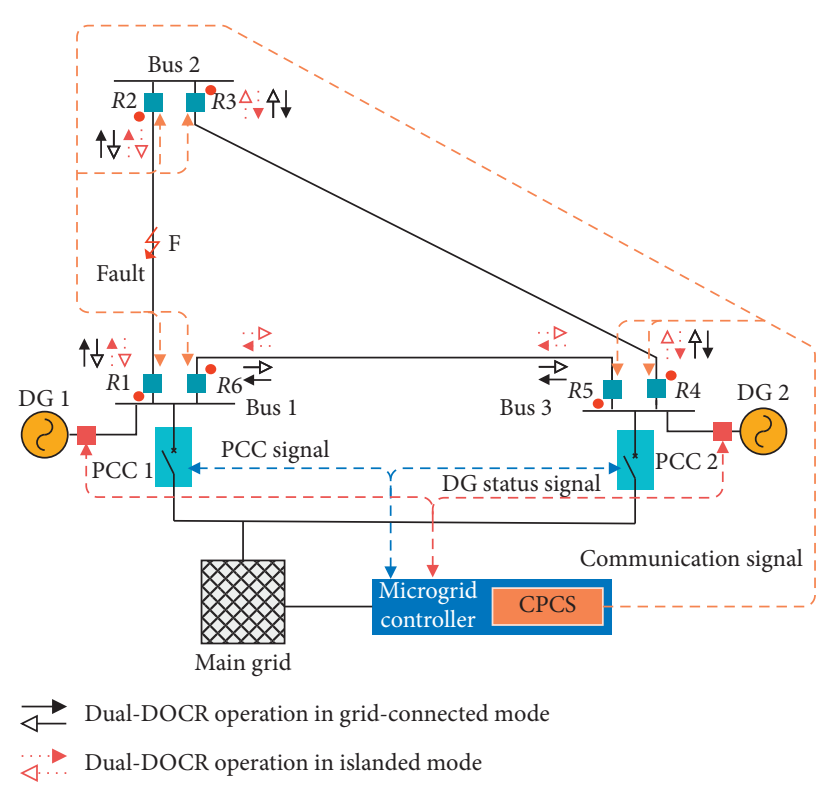

Figure 6: Structure of the centralized protection system control.

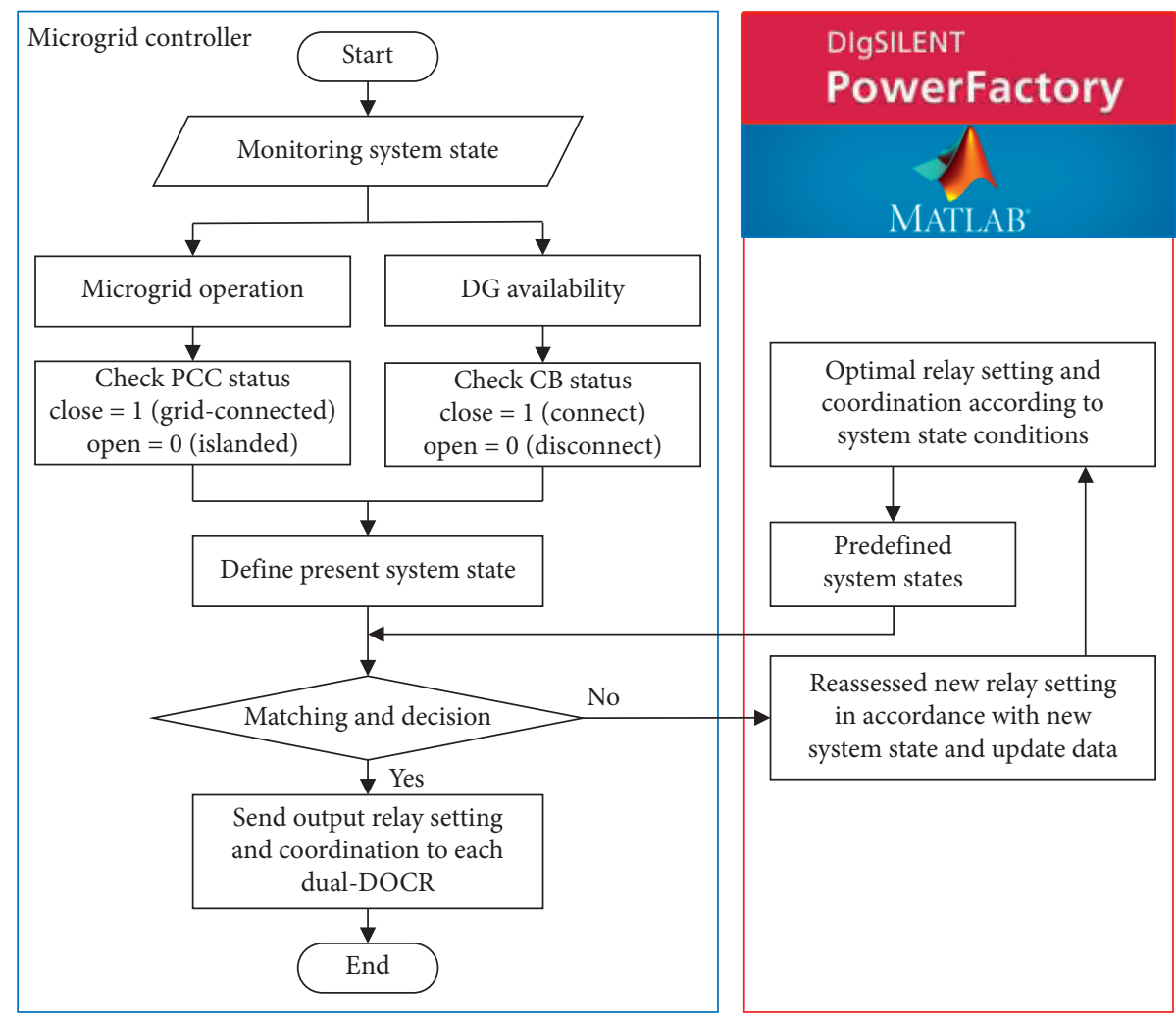

FIGURE 7: Protection system control strategy.

direction or a polarity mark can be considered to be the forward direction; otherwise, it is the reverse direction. With this approach, the dual-DOCR can respond differently for faults in both directions.

Figure 6 demonstrates a meshed microgrid operated in an islanded mode connected with two DGs. The CPCS will determine the present state of the system from the PCC status and the DG status, and then the individual relay setting group is assigned to each dual-DOCR. The protective relay is ready to operate as soon as a fault occurs in the system. In the event that a fault occurs at point $F$, the primary relay $R 1$ will operate using the $R_{\text {set }}^{4}$ operation setting of its relay setting group. The backup relay $R 6$ will operate using $R_{\text {set }}^{4}$ of its relay setting group. Besides, the primary relay $R 2$ and the backup relay $R 3$ will operate using the $R_{\text {set }}^{3}$ operation setting of each relay setting group. 


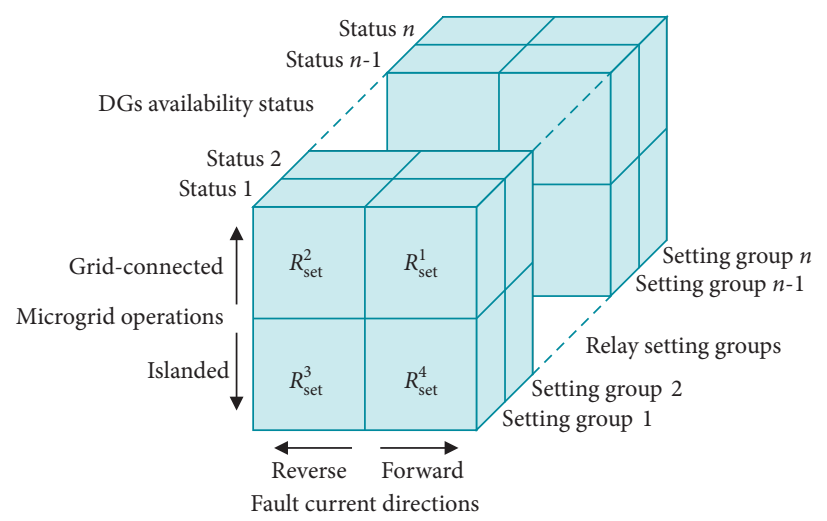

FIGURE 8: Set of relay setting groups for each dual-DOCR.

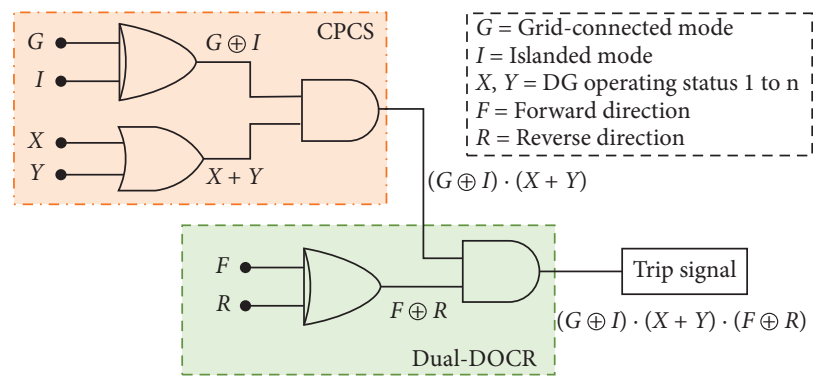

FIGURE 9: Symbolic decision-making logic for the operation of dual-DOCR.

\section{Case Studies and Results}

In this section, the proposed quaternary protection scheme implemented with the optimal setting and coordination of dual-DOCRs is evaluated and compared with the conventional protection scheme equipped with DOCRs for protecting microgrids taking into account the variation of DGs interconnection. The simulation case studies of the protection schemes are performed using the IEEE 14-bus test system with a mesh structure of $132 / 33 \mathrm{kV}$, as shown in Figure 10 . The system structure is divided into two main parts: a $132 \mathrm{kV}$ transmission system and a $33 \mathrm{kV}$ distribution system. Further system parameters and configuration are available in [25].

The $33 \mathrm{kV}$ distribution system portion equipped with two DGs, DG1 connected at bus 0006 and DG2 connected at bus 0007, is modified as a meshed microgrid that can be operated in both grid-connected and islanded modes. The microgrid connects with the main grid at the PCC located at bus numbers 0004 and 0005. Each DG is defined as a 100 MVA synchronous-based generator operated at 1.0 power factor. It is assumed that the installed DGs can supply the total system demand and the microgrid must have at least one DG to operate in the islanded mode.

The conventional protection scheme equipped with six DOCRs ( $R 1$ to $R 6)$ is implemented in the microgrid area, with the direction of each relay, which is determined according to the scheme as shown in Figure 1. On the other hand, the proposed quaternary protection scheme installed with six dual-DOCRs ( $R 1$ to $R 6$ ) is implemented in the same microgrid area, with the direction of each dual-DOCR, which is defined in accordance with the proposed scheme shown in Figure 6. The fault events $F-1$ to $F-3$ are simulated as three-phase faults occurring at the middle point of the distribution lines in the microgrid. It should be mentioned that the relay coordination needs to be considered the worst fault events at the ends of the lines. However, in the case studies, fault occurrences are simulated at the middle point of the lines to represent any faults that may occur at any location throughout the line length in meshed microgrids. In addition, the middle point fault simulation in accordance with the examples presented in Figures 2 and 4 will make it easier to understand the proposed protection approach.

System modeling and simulation are performed using DIgSILENT PowerFactory software. To study the effects of DG connection and disconnection, the simulation case studies will determine the DGs availability according to the operating status shown in Table 2. System scenarios are classified in accordance with the different operating conditions of DGs availability, protection schemes, relay settings, and protective devices, as shown in Table 3 . Tables 4 and 5 show the relevant fault currents in the grid-connected and islanded microgrid, respectively.

4.1. Conventional Protection Coordination Scheme with Directional Overcurrent Relay. These case studies demonstrate the implementation of the conventional protection scheme with DOCRs in the modified IEEE 14-bus test system. The relay settings shown in Table 6 are determined based on the IEC 60255 for the grid-connected and islanded microgrid. 


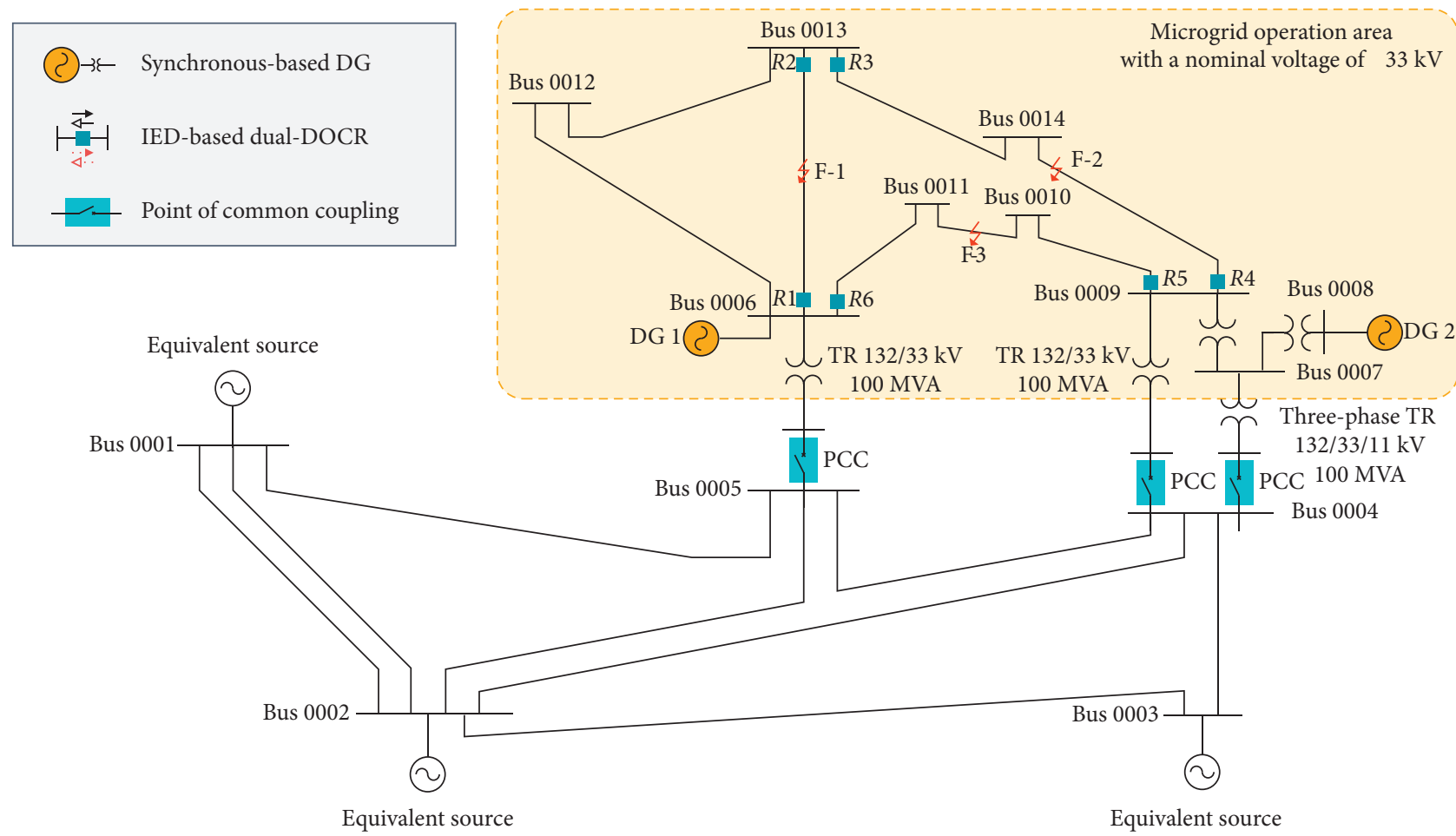

FIGURE 10: The modified distribution portion of the IEEE 14-node test feeder.

TABLE 2: Available operating status of DGs for the microgrid.

\begin{tabular}{lcc}
\hline DG availability status & DG 1 & DG 2 \\
\hline Status 1 & ON & ON \\
Status 2 & ON & OFF \\
Status 3 & OFF & ON \\
\hline
\end{tabular}

TABLE 3: Classification of the comparative case studies.

\begin{tabular}{|c|c|c|c|c|}
\hline Case study & DG operating condition & Protection scheme & Optimal relay setting & Protective device \\
\hline 1 & $\begin{array}{r}\text { Status } 1 \\
\text { Status } 2 \\
\text { Status } 3 \\
\end{array}$ & Conventional & No & DOCR \\
\hline 2 & $\begin{array}{l}\text { Status } 1 \\
\text { Status } 2 \\
\text { Status } 3 \\
\end{array}$ & Quaternary & Yes & Dual-DOCR \\
\hline
\end{tabular}

TABLE 4: Fault current magnitude in grid-connected microgrid.

\begin{tabular}{lccc}
\hline & \multicolumn{3}{c}{ Fault current $(\mathrm{kA})$ in each fault } \\
DG operating status & $F-1$ & $F-2$ & $F-3$ \\
\hline Status 1 & 11.662 & 8.226 & 8.893 \\
Status 2 & 11.181 & 7.366 & 8.110 \\
Status 3 & 7.310 & 7.156 & 7.269 \\
\hline
\end{tabular}

Tables 7 and 8 show the primary and backup relay coordination and relay operating times while protecting against fault events at $F-1$ to $F-3$ in the grid-connected and islanded microgrid. For the test results, each primary relay has more
TABLE 5: Fault current magnitude in islanded microgrid.

\begin{tabular}{lccc}
\hline & \multicolumn{3}{c}{ Fault current (kA) in each fault } \\
location \\
& $F-1$ & $F-2$ & $F-3$ \\
\hline Status 1 & 8.716 & 5.992 & 6.664 \\
Status 2 & 6.902 & 3.559 & 4.214 \\
Status 3 & 2.431 & 3.213 & 3.040 \\
\hline
\end{tabular}

than one backup relay, according to the coordination and the protection zone setting of each relay. The simulation results presented only the coordination between the primary relay and its first backup relay. 
TABLE 6: DOCR settings for conventional protection scheme.

\begin{tabular}{lcc}
\hline Relay & $I_{\mathrm{s}}(\mathrm{pu})$ & $T M S(\mathrm{~s})$ \\
\hline$R 1$ & 0.5767 & 0.1400 \\
$R 2$ & 0.5767 & 0.0500 \\
$R 3$ & 0.7150 & 0.0800 \\
$R 4$ & 0.6150 & 0.1300 \\
$R 5$ & 0.7000 & 0.1700 \\
$R 6$ & 0.6160 & 0.1300 \\
\hline
\end{tabular}

TABLE 7: Directional primary and backup relay operating times for conventional scheme in grid-connected microgrid.

\begin{tabular}{|c|c|c|c|c|}
\hline \multirow[t]{2}{*}{ DG operating status } & \multirow[t]{2}{*}{ Fault location } & \multicolumn{3}{|c|}{$\begin{array}{l}\text { Operating times }(t) \text { of } \\
\text { relay in second } \\
\left(R_{\mathrm{p}}=\text { primary relay; }\right. \\
\left.R_{\mathrm{b}}=\text { backup relay }\right)\end{array}$} \\
\hline & & $R_{\mathrm{p}}$ & $R_{\mathrm{b} 1}$ & $R_{\mathrm{b} 2}$ \\
\hline \multirow{12}{*}{ Status 1} & \multirow{4}{*}{$F-1$} & $R 1$ & $R 5$ & $R 3$ \\
\hline & & 0.278 & 0.489 & 0.577 \\
\hline & & $R 2$ & $R 4$ & $R 6$ \\
\hline & & 0.129 & 0.349 & 0.446 \\
\hline & \multirow{4}{*}{$F-2$} & $R 3$ & $R 1$ & $R 5$ \\
\hline & & 0.200 & 0.415 & 0.514 \\
\hline & & $R 4$ & R6 & $R 2$ \\
\hline & & 0.259 & 0.471 & 0.499 \\
\hline & \multirow{4}{*}{$F-3$} & $R 5$ & $R 3$ & $R 1$ \\
\hline & & 0.338 & 0.548 & 1.236 \\
\hline & & R6 & $R 2$ & $R 4$ \\
\hline & & 0.272 & 0.580 & 0.799 \\
\hline \multirow{12}{*}{ Status 2} & \multirow{4}{*}{$F-1$} & $R 1$ & $R 5$ & $R 3$ \\
\hline & & 0.278 & 0.546 & 0.586 \\
\hline & & $R 2$ & $R 4$ & $R 6$ \\
\hline & & 0.133 & 0.369 & 0.509 \\
\hline & \multirow{4}{*}{$F-2$} & $R 3$ & $R 1$ & $R 5$ \\
\hline & & 0.202 & 0.420 & 0.484 \\
\hline & & $R 4$ & R6 & $R 2$ \\
\hline & & 0.259 & 0.439 & 0.591 \\
\hline & \multirow{4}{*}{$F-3$} & $R 5$ & $R 3$ & $R 1$ \\
\hline & & 0.338 & 0.550 & 1.048 \\
\hline & & $R 6$ & $R 2$ & $R 4$ \\
\hline & & 0.274 & 0.522 & 0.636 \\
\hline \multirow{12}{*}{ Status 3} & \multirow{4}{*}{$F-1$} & $R 1$ & $R 5$ & $R 3$ \\
\hline & & 0.278 & 0.493 & 0.602 \\
\hline & & $R 2$ & $R 4$ & $R 6$ \\
\hline & & 0.142 & 0.360 & 0.397 \\
\hline & \multirow{4}{*}{$F-2$} & $R 3$ & $R 1$ & $R 5$ \\
\hline & & 0.226 & 0.480 & 0.833 \\
\hline & & $R 4$ & $R 6$ & $R 2$ \\
\hline & & 0.259 & 0.649 & 0.679 \\
\hline & \multirow{4}{*}{$F-3$} & R5 & $R 3$ & $R 1$ \\
\hline & & 0.338 & 0.553 & 0.812 \\
\hline & & $R 6$ & $R 2$ & $R 4$ \\
\hline & & 0.309 & 0.525 & 0.788 \\
\hline
\end{tabular}

When the microgrid operates in either grid-connected or islanded mode with both DGs supplying power to the system, the operating times of the DOCRs for protecting against faults show that all relays in the microgrid are coordinated correctly without violating the CTI constraint. For example, in Table 7 , when a fault occurs at F-3 in the grid-connected mode with DG status 1, the operating time of
TABLE 8: Directional primary and backup relay operating times for conventional scheme in islanded microgrid.

\begin{tabular}{|c|c|c|c|c|}
\hline \multirow[t]{2}{*}{ DG operating status } & \multirow[t]{2}{*}{ Fault location } & \multicolumn{3}{|c|}{$\begin{array}{c}\text { Operating times }(t) \text { of } \\
\text { relay in second } \\
\left(R_{\mathrm{p}}=\text { primary relay; }\right. \\
\left.R_{\mathrm{b}}=\text { backup relay }\right)\end{array}$} \\
\hline & & $R_{\mathrm{p}}$ & $R_{\mathrm{b} 1}$ & $R_{\mathrm{b} 2}$ \\
\hline \multirow{12}{*}{ Status 1} & \multirow{4}{*}{$F-1$} & $R 1$ & $R 5$ & $R 3$ \\
\hline & & 0.278 & 0.549 & 0.637 \\
\hline & & $R 2$ & $R 4$ & $R 6$ \\
\hline & & 0.145 & 0.392 & 0.507 \\
\hline & \multirow{4}{*}{$F-2$} & $R 3$ & $R 1$ & $R 5$ \\
\hline & & 0.210 & 0.438 & 0.466 \\
\hline & & $R 4$ & R6 & $R 2$ \\
\hline & & 0.259 & 0.490 & 0.518 \\
\hline & \multirow{4}{*}{$F-3$} & R5 & R3 & $R 1$ \\
\hline & & 0.338 & 0.582 & 1.018 \\
\hline & & R6 & $R 2$ & $R 4$ \\
\hline & & 0.286 & 0.601 & 0.691 \\
\hline \multirow{12}{*}{ Status 2} & \multirow{4}{*}{$F-1$} & $R 1$ & $R 5$ & $R 3$ \\
\hline & & 0.278 & 1.106 & 1.188 \\
\hline & & $R 2$ & $R 4$ & $R 6$ \\
\hline & & 0.203 & 0.995 & 1.139 \\
\hline & \multirow{4}{*}{$F-2$} & $R 3$ & $R 1$ & $R 5$ \\
\hline & & 0.216 & 0.460 & 0.493 \\
\hline & & $R 4$ & $R 6$ & $R 2$ \\
\hline & & 0.333 & 0.557 & 0.611 \\
\hline & \multirow{4}{*}{$F-3$} & $R 5$ & $R 3$ & $R 1$ \\
\hline & & 0.508 & 0.873 & 0.893 \\
\hline & & $R 6$ & $R 2$ & $R 4$ \\
\hline & & 0.291 & 0.517 & 0.556 \\
\hline \multirow{12}{*}{ Status 3} & \multirow{4}{*}{$F-1$} & $R 1$ & $R 5$ & $R 3$ \\
\hline & & 0.474 & 0.696 & 0.699 \\
\hline & & $R 2$ & $R 4$ & $R 6$ \\
\hline & & 0.189 & 0.418 & 0.443 \\
\hline & \multirow{4}{*}{$F-2$} & $R 3$ & $R 1$ & $R 5$ \\
\hline & & 0.616 & 2.000 & 2.010 \\
\hline & & $R 4$ & R6 & $R 2$ \\
\hline & & 0.283 & 1.090 & 1.102 \\
\hline & \multirow{4}{*}{$F-3$} & R5 & $R 3$ & $R 1$ \\
\hline & & 0.363 & 0.601 & 1.252 \\
\hline & & $R 6$ & $R 2$ & $R 4$ \\
\hline & & 0.867 & 1.086 & 1.099 \\
\hline
\end{tabular}

the primary relay $R 6$ and its backup relays $R 2$ and $R 4$ is $0.272,0.580$, and $0.799 \mathrm{sec}$, respectively. Besides, in Table 8 , when the fault occurs in the islanded microgrid, the time of the primary relay $R 6$ and its backup relays $R 2$ and $R 4$ is $0.286,0.601$, and $0.691 \mathrm{sec}$, respectively. The operating time of the primary relay which is less than that of the secondary relay indicates that the primary relay will operate before its backup in accordance with the principle of protection coordination.

For the grid-connected operation with only one DG connected to the microgrid, DG operating status 2 and 3, test results in Table 7 show that all primary and backup relays can be still coordinated. For example, when a fault occurs at $F-3$ in the grid-connected microgrid with DG operating status 3, the operating time of the primary relay $R 6$ and its backup relays $R 2$ and $R 4$ is $0.309,0.525$, and $0.788 \mathrm{sec}$, 
TABLE 9: Dual-directional overcurrent relay settings for the quaternary protection coordination scheme.

\begin{tabular}{|c|c|c|c|c|c|c|c|c|c|}
\hline \multirow[t]{2}{*}{ Relay } & \multirow[t]{2}{*}{ DG operating } & \multicolumn{2}{|c|}{$\begin{array}{l}\text { Grid-connected } \\
\text { microgrid in forward } \\
\text { direction }\end{array}$} & \multicolumn{2}{|c|}{$\begin{array}{l}\text { Grid-connected } \\
\text { microgrid in reverse } \\
\text { direction }\end{array}$} & \multicolumn{2}{|c|}{$\begin{array}{l}\text { Islanded microgrid in } \\
\text { forward direction }\end{array}$} & \multicolumn{2}{|c|}{$\begin{array}{l}\text { Islanded microgrid in } \\
\text { reverse direction }\end{array}$} \\
\hline & & $I_{\mathrm{s}}(\mathrm{pu})$ & TMS (s) & $I_{\mathrm{s}}(\mathrm{pu})$ & TMS (s) & $I_{\mathrm{s}}(\mathrm{pu})$ & TMS (s) & $I_{\mathrm{s}}(\mathrm{pu})$ & TMS (s) \\
\hline \multirow{3}{*}{$R 1$} & Status 1 & 0.908971 & 0.050000 & 0.830400 & 0.050000 & 0.870798 & 0.065532 & 0.774000 & 0.050000 \\
\hline & Status 2 & 0.920024 & 0.050000 & 0.752000 & 0.050000 & 0.926764 & 0.050706 & 0.812000 & 0.050000 \\
\hline & Status 3 & 0.816757 & 0.050000 & 0.891734 & 0.050000 & 0.651192 & 0.057826 & 0.578151 & 0.386953 \\
\hline \multirow{3}{*}{$R 2$} & Status 1 & 0.842845 & 0.134825 & 0.961430 & 0.050535 & 0.774384 & 0.096503 & 0.892387 & 0.056220 \\
\hline & Status 2 & 0.772070 & 0.128937 & 0.832167 & 0.050000 & 0.813987 & 0.094885 & 0.822938 & 0.050000 \\
\hline & Status 3 & 0.851258 & 0.118257 & 0.970237 & 0.050000 & 0.552425 & 0.192863 & 0.582199 & 0.050016 \\
\hline \multirow{3}{*}{ R3 } & Status 1 & 0.922905 & 0.050000 & 0.870209 & 0.143880 & 0.841449 & 0.050000 & 0.857803 & 0.074514 \\
\hline & Status 2 & 0.808935 & 0.050000 & 0.888088 & 0.120719 & 0.902977 & 0.050000 & 0.803077 & 0.050000 \\
\hline & Status 3 & 0.859760 & 0.050000 & 0.929486 & 0.139762 & 0.895631 & 0.050187 & 0.819987 & 0.111881 \\
\hline \multirow{3}{*}{$R 4$} & Status 1 & 0.738000 & 0.057891 & 0.771048 & 0.050004 & 0.761133 & 0.056368 & 0.767017 & 0.055154 \\
\hline & Status 2 & 0.847584 & 0.077759 & 0.869435 & 0.050000 & 0.804075 & 0.167440 & 0.859151 & 0.052559 \\
\hline & Status 3 & 0.811748 & 0.050000 & 0.850455 & 0.050000 & 0.769846 & 0.050000 & 0.880659 & 0.050052 \\
\hline \multirow{3}{*}{$R 5$} & Status 1 & 0.990237 & 0.056325 & 0.901277 & 0.115700 & 0.833758 & 0.052783 & 0.890626 & 0.050322 \\
\hline & Status 2 & 0.729298 & 0.050000 & 0.728047 & 0.159616 & 0.796449 & 0.050000 & 0.901522 & 0.086345 \\
\hline & Status 3 & 0.818587 & 0.050000 & 0.726000 & 0.064150 & 0.869643 & 0.056577 & 0.801000 & 0.050000 \\
\hline \multirow{3}{*}{$R 6$} & Status 1 & 0.739626 & 0.102973 & 0.777452 & 0.050251 & 0.811765 & 0.050000 & 0.869746 & 0.064470 \\
\hline & Status 2 & 0.750279 & 0.078815 & 0.850592 & 0.050000 & 0.800000 & 0.050000 & 0.953794 & 0.050007 \\
\hline & Status 3 & 0.715141 & 0.122780 & 0.760580 & 0.050000 & 0.860723 & 0.084716 & 0.810000 & 0.050000 \\
\hline
\end{tabular}

respectively. It is observed that the relay operating times obtained from the DG status 2 and 3 are close to the times obtained from the DG status 1 . These results indicate that when a fault occurs in the grid-connected microgrid, the dominated fault currents are from the main grid, which is higher than those from DGs. Disconnecting one of the DGs from the microgrid has little impact on the total system fault current magnitudes. The protective relays can still operate normally with the corresponding relay operation times.

For the islanded operation with only one DG connected to the microgrid, DG status 2 and 3, test results in Table 8 show that all relay coordination can be satisfied. For example, when a fault occurs at F-3 in the islanded microgrid with DG operating status 3 , the operating time of the primary relay $R 6$ and its backup relays $R 2$ and $R 4$ is $0.867,1.086$, and $1.099 \mathrm{sec}$, respectively. It is observed that the relay operating times obtained from the islanded microgrid are higher than those from the grid connection.

These results indicate that when a fault occurs in the islanded microgrid, all fault currents are from the DGs, which are much lower compared to the grid-connected operation. Disconnecting one of the DGs from the islanded microgrid has much impact on the total system fault current levels and magnitudes. Using relay settings based on grid-connected mode causes the operating time of the relays to slow down when protecting the islanding, especially for the backup relays, which may lead to protection blinding problems.

4.2. Quaternary Protection Coordination Scheme with DualDirectional Overcurrent Relay. For evaluating the performance of the quaternary protection scheme presented in Section 3, the implementation of the proposed scheme with dual-DOCRs in the IEEE 14-bus test system is demonstrated in this section. Each dual-DOCR is equipped with a relay setting group that is optimally determined according to the present system state. Each relay setting group consists of four pairs of relay setting values $\left(I_{\mathrm{S}}^{n}, \mathrm{TMS}^{n}\right)$ in accordance with the microgrid operations and the fault current directions.

The optimal dual-DOCRs settings shown in Table 9 are determined based on system state variations that take into account the microgrid operations, DG availability, and fault current directions. It can be seen that each dual-DOCR has three relay setting groups according to the operating status of the DGs availability. Each relay setting group will have different relay setting values depending on the short-circuit current level and magnitude that are caused by the operations of the microgrid and DGs. In particular, the short-circuit current level in the islanded mode, which is lower than that of the grid-connection mode, causes the relay setting values to be reduced accordingly to improve the sensitivity of the protection system. Thus, the protective relay settings obtained from the proposed scheme are more suitable and responsive to the flexible operations of the microgrid with DGs, which have dynamic variations of shortcircuit current levels, magnitudes, and directions.

Tables 10 and 11 show the primary and backup relay coordination and relay operating times while protecting against fault events at F-1 to F-3 in the grid-connected and islanded microgrid.

For example, in Table 10, when a fault occurs at F-3 in the grid-connected microgrid with DG status 1, the operating time of the primary relay $R 6$ and its backup relays $R 1$ and $R 2$ is 0.124 , 0.466 , and $0.475 \mathrm{sec}$, respectively. Besides, in Table 11 , when the fault occurs in the islanded microgrid, the time of the primary relay $R 6$ and its backup relays $R 1$ and $R 2$ is $0.196,0.531$, and $0.548 \mathrm{sec}$, respectively. The simulation results of the relay operating times show that the optimal protection coordination obtained from the proposed approach can be successfully used 
TABLE 10: Dual-directional primary and backup relay operating times for quaternary scheme in grid-connected microgrid.

\begin{tabular}{|c|c|c|c|c|}
\hline \multirow[t]{2}{*}{ DG operating status } & \multirow[t]{2}{*}{ Fault location } & \multicolumn{3}{|c|}{$\begin{array}{c}\text { Operating times }(t) \text { of } \\
\text { relay in second } \\
\left(R_{\mathrm{p}}=\text { primary relay; }\right. \\
\left.R_{\mathrm{b}}=\text { backup relay }\right)\end{array}$} \\
\hline & & $R_{\mathrm{p}}$ & $R_{\mathrm{b} 1}$ & $R_{\mathrm{b} 2}$ \\
\hline \multirow{12}{*}{ Status 1} & \multirow{4}{*}{$F-1$} & $R 1$ & $R 6$ & $R 5$ \\
\hline & & 0.099 & 0.399 & 0.410 \\
\hline & & $R 2$ & $R 3$ & $R 4$ \\
\hline & & 0.163 & 0.453 & 0.466 \\
\hline & \multirow{4}{*}{$F-2$} & $R 3$ & $R 2$ & $R 1$ \\
\hline & & 0.139 & 0.440 & 0.454 \\
\hline & & $R 4$ & $R 5$ & $R 6$ \\
\hline & & 0.099 & 0.408 & 0.421 \\
\hline & \multirow{4}{*}{$F-3$} & $R 5$ & $R 4$ & $R 3$ \\
\hline & & 0.119 & 0.425 & 0.440 \\
\hline & & $R 6$ & $R 1$ & $R 2$ \\
\hline & & 0.124 & 0.466 & 0.475 \\
\hline \multirow{12}{*}{ Status 2} & \multirow{4}{*}{$F-1$} & $R 1$ & $R 6$ & $R 5$ \\
\hline & & 0.099 & 0.405 & 0.418 \\
\hline & & $R 2$ & $R 3$ & $R 4$ \\
\hline & & 0.157 & 0.473 & 0.492 \\
\hline & \multirow{4}{*}{$F-2$} & $R 3$ & $R 2$ & $R 1$ \\
\hline & & 0.146 & 0.450 & 0.463 \\
\hline & & $R 4$ & $R 5$ & $R 6$ \\
\hline & & 0.099 & 0.393 & 0.412 \\
\hline & \multirow{4}{*}{$F-3$} & $R 5$ & $R 4$ & $R 3$ \\
\hline & & 0.099 & 0.394 & 0.404 \\
\hline & & $R 6$ & $R 1$ & $R 2$ \\
\hline & & 0.126 & 0.580 & 0.601 \\
\hline \multirow{12}{*}{ Status 3} & \multirow{4}{*}{$F-1$} & $R 1$ & $R 6$ & $R 5$ \\
\hline & & 0.104 & 0.412 & 0.425 \\
\hline & & $R 2$ & $R 3$ & $R 4$ \\
\hline & & 0.167 & 0.468 & 0.472 \\
\hline & \multirow{4}{*}{$F-2$} & $R 3$ & $R 2$ & $R 1$ \\
\hline & & 0.153 & 0.461 & 0.478 \\
\hline & & $R 4$ & R5 & $R 6$ \\
\hline & & 0.099 & 0.404 & 0.417 \\
\hline & \multirow{4}{*}{$F-3$} & $R 5$ & $R 4$ & $R 3$ \\
\hline & & 0.102 & 0.448 & 0.466 \\
\hline & & $R 6$ & $R 1$ & $R 2$ \\
\hline & & 0.129 & 0.461 & 0.474 \\
\hline
\end{tabular}

to coordinate the primary and backup relays without violating any coordination constraints. In addition, the relay operating times obtained from the quaternary scheme are lower than those from the conventional scheme, which indicates the improving sensitivity and speed of the protection system.

For the grid-connected operation with only one DG connected to the microgrid, DG operating status 2 and 3, test results in Table 10 show that all primary and backup relays are coordinated correctly. For example, when a fault occurs at $F-3$ in the grid-connected microgrid with DG status 3, the operating time of the primary relay $R 6$ and its backup relays $R 1$ and $R 2$ is $0.129,0.461$, and $0.474 \mathrm{sec}$, respectively. In addition, for the islanded operation with only one DG connected to the microgrid, DG status 2 and 3, test results are shown in Table 11. For example, when a fault occurs at
TABLE 11: Dual-directional primary and backup relay operating times for quaternary scheme in islanded microgrid.

\begin{tabular}{|c|c|c|c|c|}
\hline \multirow[t]{2}{*}{ DG operating status } & \multirow[t]{2}{*}{ Fault location } & \multicolumn{3}{|c|}{$\begin{array}{c}\text { Operating times }(t) \text { of } \\
\text { relay in second } \\
\left(R_{\mathrm{p}}=\text { primary relay; }\right. \\
\left.R_{\mathrm{b}}=\text { backup relay }\right)\end{array}$} \\
\hline & & $R_{\mathrm{p}}$ & $R_{\mathrm{b} 1}$ & $R_{\mathrm{b} 2}$ \\
\hline \multirow{12}{*}{ Status 1} & \multirow{4}{*}{$F-1$} & $R 1$ & $R 6$ & $R 5$ \\
\hline & & 0.172 & 0.499 & 0.518 \\
\hline & & $R 2$ & $R 3$ & $R 4$ \\
\hline & & 0.138 & 0.522 & 0.532 \\
\hline & \multirow{4}{*}{$F-2$} & $R 3$ & $R 2$ & $R 1$ \\
\hline & & 0.259 & 0.532 & 0.553 \\
\hline & & $R 4$ & R5 & $R 6$ \\
\hline & & 0.152 & 0.439 & 0.461 \\
\hline & \multirow{4}{*}{$F-3$} & $R 5$ & $R 4$ & R3 \\
\hline & & 0.212 & 0.501 & 0.505 \\
\hline & & $R 6$ & $R 1$ & $R 2$ \\
\hline & & 0.196 & 0.531 & 0.548 \\
\hline \multirow{12}{*}{ Status 2} & \multirow{4}{*}{$F-1$} & $R 1$ & $R 6$ & $R 5$ \\
\hline & & 0.144 & 0.484 & 0.497 \\
\hline & & $R 2$ & $R 3$ & $R 4$ \\
\hline & & 0.540 & 0.787 & 0.805 \\
\hline & \multirow{4}{*}{$F-2$} & $R 3$ & $R 2$ & $R 1$ \\
\hline & & 0.309 & 0.610 & 0.623 \\
\hline & & $R 4$ & $R 5$ & $R 6$ \\
\hline & & 0.179 & 0.465 & 0.476 \\
\hline & \multirow{4}{*}{$F-3$} & $R 5$ & $R 4$ & $R 3$ \\
\hline & & 0.406 & 0.715 & 0.728 \\
\hline & & $R 6$ & $R 1$ & $R 2$ \\
\hline & & 0.264 & 0.564 & 0.578 \\
\hline \multirow{12}{*}{ Status 3} & \multirow{4}{*}{$F-1$} & $R 1$ & $R 6$ & $R 5$ \\
\hline & & 0.136 & 0.432 & 0.445 \\
\hline & & $R 2$ & R3 & $R 4$ \\
\hline & & 0.117 & 0.428 & 0.443 \\
\hline & \multirow{4}{*}{$F-2$} & $R 3$ & $R 2$ & $R 1$ \\
\hline & & 0.514 & 0.828 & 0.837 \\
\hline & & $R 4$ & $R 5$ & $R 6$ \\
\hline & & 0.219 & 0.509 & 0.530 \\
\hline & \multirow{4}{*}{$F-3$} & $R 5$ & $R 4$ & R3 \\
\hline & & 0.296 & 0.601 & 0.620 \\
\hline & & $R 6$ & $R 1$ & $R 2$ \\
\hline & & 0.238 & 0.548 & 0.561 \\
\hline
\end{tabular}

TABLE 12: Comparison of the total relay operating times of different protection schemes in grid-connected microgrid.

\begin{tabular}{lccc}
\hline & \multicolumn{2}{c}{ Total relay operating } \\
times (s) & $\begin{array}{c}\text { Percentage of } \\
\text { reduction }\end{array}$ \\
& $\begin{array}{c}\text { Conventional } \\
\text { scheme }\end{array}$ & $\begin{array}{c}\text { Quaternary } \\
\text { scheme }\end{array}$ & \\
\hline Status 1 & 8.399 & 6.000 & 28.56 \\
Status 2 & 8.184 & 6.211 & 24.11 \\
Status 3 & 8.723 & 6.140 & 29.61 \\
\hline
\end{tabular}

F-3 in the islanded microgrid with DG operating status 3, the operating time of the primary relay $R 6$ and its backup relays $R 1$ and $R 2$ is $0.238,0.548$, and $0.561 \mathrm{sec}$, respectively.

The comparison of the total relay operating times obtained from the conventional and the proposed protection 
TABLE 13: Comparison of the total relay operating times of different protection schemes in islanded microgrid.

\begin{tabular}{lccc}
\hline \multirow{2}{*}{ DG operating status } & \multicolumn{2}{c}{ Total relay operating times (s) } & Percentage of reduction \\
& Conventional scheme & Quaternary scheme & 13.50 \\
Status 1 & 8.405 & 7.270 & 18.21 \\
Status 2 & 11.217 & 9.174 & 45.70 \\
Status 3 & 15.288 & 8.302 & 4 \\
\hline
\end{tabular}

schemes is summarized in Tables 12 and 13 for the gridconnected and islanded modes of operation, respectively. It is observed that the coordination of all relays can be achieved efficiently, as seen from the much faster operating time of the protective relays when compared with the conventional scheme.

\section{Conclusion}

The operation of microgrids in islanded mode causes the short-circuit current to be lower than the operation in gridconnected microgrid due to only the DGs installed in the islanding, which supplies the fault current. In addition, the existence of DGs in the microgrids causes changes in the short-circuit current magnitudes and directions from the connection and disconnection of the DGs. These changes affect the performance of conventional protection systems that are designed based on the grid-connected microgrid. In this paper, the quaternary protection scheme with dualDOCRs is proposed for protecting against faults in meshed microgrids with the interconnection of DGs. The optimal relay setting and coordination are determined using an EP approach to minimize the relay operating times, improving the speed of the protection system operation. The proposed protection approach is implemented with a centralized protection control system based on the smart grid concept to increase the adaptability of the dual-DOCRs. The simulation case studies of the protection scheme are performed using the modified IEEE 14-bus test system. Scenarios, including possible operations of microgrids, DGs availability, and different fault events, are analyzed and discussed.

The simulation results and analytical studies show that the use of the quaternary protection scheme with dualDOCRs coordinated optimally according to the operations of microgrids and DGs availabilities can increase the response-ability of the protection system, which can be observed from the significant reduction in the relay operating times. In addition, the primary and backup relays can be coordinated efficiently for protecting microgrids and DGs without violating protection system constraints. These performances led to the enhancement of selectivity, sensitivity, and speed of the microgrid protection system.

\section{Data Availability}

All relevant data including relay setting and coordination and relay operating time are included in the article. The additional data regarding the IEEE 14-bus test system and relay modeling in DigSILENT PowerFactory 2019, student license, used to support the findings of this study are available from the corresponding author upon request.

\section{Disclosure}

The funding organizations had no role in the design of the study and collection, analysis, and interpretation of the data or writing of the manuscript.

\section{Conflicts of Interest}

The authors declare there are no conflicts of interest regarding the publication of this paper.

\section{Acknowledgments}

The authors would like to thank the Energy Policy Planning Office, Ministry of Energy, Thailand, in addition to the Faculty of Engineering and the Graduate School, Chiang Mai University, Thailand, for financial supports.

\section{References}

[1] Working group D3, "Impact of distributed resources on distribution relay protection," A report to the Line Protection Subcommittee of the Power System Relay Committee of The IEEE Power Engineering Society, Piscataway, NJ, USA, 2004.

[2] E. J. Coster, J. M. A. Myrzik, B. Kruimer, and W. L. Kling, "Integration issues of distributed generation in distribution grids," Proceedings of the IEEE, vol. 99, no. 1, pp. 28-39, 2011.

[3] D. Jones and J. J. Kumm, "Future distribution feeder protection using directional overcurrent elements," IEEE Transactions on Industry Applications, vol. 50, no. 2, pp. 1385-1390, 2014.

[4] H. H. Zeineldin, H. M. Sharaf, D. K. Ibrahim, and E. E. A. ElZahab, "Optimal protection coordination for meshed distribution systems with DG using dual setting directional overcurrent relays," IEEE Transactions on Smart Grid, vol. 6, no. 1, pp. 115-123, 2015.

[5] A. Yazdaninejadi, S. Golshannavaz, and D. Nazarpour, "Dualsetting directional overcurrent relays for protecting automated distribution networks," IEEE Transactions on Industrial Informatics, vol. 15, no. 2, pp. 730-740, 2019.

[6] E. Ebrahimi, M. J. Sanjari, and G. B. Gharehpetian, "Control of three-phase inverter-based DG system during fault condition without changing protection coordination," International Journal of Electrical Power \& Energy Systems, vol. 63, pp. 814-823, 2014.

[7] IEEE Standards Coordinating Committee 21, IEEE Std. 1547.6 Recommended Practice for Interconnecting Distributed Resources with Electric Power Systems Distribution Secondary Networks, 2011.

[8] J. M. Gers and E. J. Holmes, Protection of Electricity Distribution Networks, Institution of Electrical Engineers, London, UK, 2nd edition, 2004. 
[9] PE/PSRCC-Power System Relaying and Control, IEEE C37.112 Standard for Inverse-Time Characteristics Equations for Overcurrent Relays, 2018.

[10] A. Zamani, T. Sidhu, and A. Yazdani, "A strategy for protection coordination in radial distribution networks with distributed generators," in Proceedings of the IEEE PES General Meeting, Minneapolis, MN, USA, July 2010.

[11] S. A. Saleh, "Signature-coordinated digital multi relay protection for microgrid systems," IEEE Transactions on Power Electronics, vol. 29, no. 9, pp. 4614-4623, 2014.

[12] W. K. A. Najy, H. H. Zeineldin, and W. L. Woon, "Optimal protection coordination for microgrids with grid-connected and islanded capability," IEEE Transactions on Industrial Electronics, vol. 60, no. 4, pp. 1668-1677, 2013.

[13] M. Mansour, S. Mekhamer, and N.-S. El-Kharbawe, "A modified particle swarm optimizer for the coordination of directional overcurrent relays," IEEE Transactions on Power Delivery, vol. 22, no. 3, pp. 1400-1410, 2007.

[14] P. P. Bedekar and S. R. Bhide, "Optimum coordination of overcurrent relay timing using continuous genetic algorithm," Expert Systems with Applications, vol. 38, no. 9, pp. 1128611292, 2011.

[15] J. Jager, T. Keli, L. Shang, and R. Krebs, "New protection coordination methods in the presence of distributed generation," in Proceedings of the Eighth IEE International Conference on Developments in Power System Protection, Amsterdam, The Netherlands, April 2004.

[16] N. Jenkins, G. Strbac, J. A. Pecas Lope et al., "Large scale integration of microgeneration to low voltage grids, protection guidelines for a micro-grid," in Proceedings of the Conseil International des Grands Réseaux Electriques, Paris, France, August 2006.

[17] H. Al-Nasseri and M. A. Redfern, "Harmonics content based protection scheme for micro-grids dominated by solid state converters," in Proceedings of the 12th International MiddleEast in Power System, Aswan, Egypt, March 2008.

[18] H. Al-Nasseri, M. A. Redfern, and F. Li, "A voltage based protection for micro-grids containing power electronic converter," in Proceedings of the IEEE Power Engineering Society General Meeting, Montreal, Canada, June 2006.

[19] H. Nikkhajoei and R. H. Lasseter, "Microgrid protection," in Proceedings of the IEEE Power Engineering Society General Meeting, Atlanta, GA, USA, August 2007.

[20] M. A. Zamani, T. S. Sidhu, and A. Yazdani, "A protection strategy and microprocessor-based relay for low-voltage microgrids," IEEE Transactions on Power Delivery, vol. 26, no. 3, pp. 1873-1883, 2011.

[21] T. S. Ustun, C. Ozansoy, and A. Zayegh, "Modeling of a centralized microgrid protection system and distributed energy resources according to IEC 61850-7-420," IEEE Transactions on Power Systems, vol. 27, no. 3, pp. 1560-1567, 2012.

[22] H. Laaksonen, D. Ishchenko, and A. Oudalov, "Adaptive protection and microgrid control design for Hailuoto island," IEEE Transactions on Smart Grid, vol. 5, no. 3, pp. 1486-1493, 2014.

[23] Alstom Grid, Network Protection \& Automation Guide, Alstom Grid Worldwide Contact Centre, Saint-Ouen, France, 2011.

[24] P. Srisathian and P. Jirapong, "Optimal capacitor allocation for power transfer capability and power loss improvements in power transmission systems using evolutionary programming," in Proceedings of the 8th Electrical Engineering/ Electronics, Computer, Telecommunications and Information
Technology (ECTI) Association of Thailand, Khon Kaen, Thailand, May 2011.

[25] Dynamic IEEE Test System by Center for Intelligent Systems \& Networks (KOIOS) and University of Cyprus, https://www.kios. ucy.ac.cy/testsystems/index.php/dynamic-ieee-test-systems/ieee14-bus-modified-test-system. 